\title{
Martin Woodrow: 'I think the profession has done itself proud'
}

Interview by Adrian O'Dowd

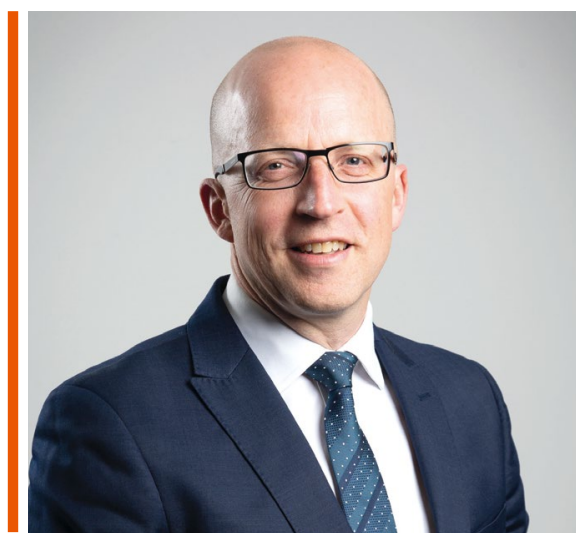

\section{What is your background?}

Bournemouth is my home town - that's where I was born and grew up. Both my parents still live there and it was a nice place to grow up.

\section{Can you tell me a little bit about your} non-professional life-family, hobbies, life outside the job?

I am married and we have two children aged ten and 12. They were both born up in Edinburgh and we now live in fairly rural Hampshire.

I've always been a bit of a sports-mad person and I used to play a lot of football and cricket, and now I play golf and try to keep fit by running. I've done a few marathons.

Throughout the year during this lockdown, I do find it quite therapeutic to go out and get some exercise and do some running. Nobody in my family was a dentist! My parents both started working life as hairdressers.

\section{What was your first job after graduating from University College London in 1990 ? \\ My first job after graduating was as a labourer on various building sites in London just trying to earn some money. It was that time when there was a lot of building}

\author{
Martin Woodrow joined the British Dental Association (BDA) in 2013 and \\ has risen in the organisation to become its Chief Executive, taking over \\ the post permanently in February of last year. Despite presiding through a \\ dramatic and highly challenging first year, Martin's extensive experience of \\ trade union work has served him well in supporting and guiding dentists \\ through the COVID-19 pandemic.
}

renovations so we did the renovating of old blocks of flats and old buildings in Pimlico in London.

\section{After a stint working at the Polytechnics and Colleges Funding Council, you joined the British Medical Association (BMA) in 1993 - what drew you to work with a trade union?}

Coming out of university, I wasn't that clear about what to do but I was interested in policy work and that's when I went into that quasi civil service job at the Polytechnics and Colleges Funding Council.

I then saw a job advertised at the BMA initially in policy development, so I got involved in doing that and I liked it. Gradually, I got involved in contract and pay negotiation activity and then developed an interest in industrial relations work representing members in their individual circumstances in discussions and negotiations with employers.

Gradually, I found my way into more senior jobs. I did an MBA (completed in 2008) and was promoted to more senior roles. I was appointed as what was then called the Scottish secretary - the director for the BMA in Scotland - and moved up to Edinburgh.
Did you enjoy your time in Scotland?

I did love living in Edinburgh. It's a great city to live in, it's beautiful and it's got everything you want from a city. I'm quite a keen golfer and there is plenty of good quality golf around there which was really appealing.

You must have learned a lot during your 16 years at the BMA - what is the most useful thing you learned?

Having left the BMA, and from a BDA perspective, what's quite interesting is the perception amongst professional associations and amongst trade unions of the BMA as being a powerful, successful trade union and professional body on behalf of its members.

I have met dentists who say 'I wish that the BDA was a bit more like the BMA'.

The two organisations are fundamentally different in terms of their size and their reach but what is interesting is how the perception of the BMA externally, as this all-powerful organisation, is certainly not shared by doctors universally.

Nevertheless, it was a great experience at the BMA. I was lucky to be involved in quite a wide range of things from advising and representing individual members to more collective work. You really see in 
14 that role how important that kind of individual representation of members is and you've got the livelihood of an individual member in your hands when you are representing them at a disciplinary hearing.

One of the big pieces of work I did it at the BMA was a set piece NHS consultant contract negotiation that was covering thousands of members. When I was in Scotland, we had industrial action relating to NHS pensions and we were organising and dealing with that and interacting with senior politicians.

\section{What drew you to joining the BDA in 2013, initially as Director of Policy and Professional Services?}

I'd been at the BMA for some time and it felt like it was time to broaden my horizons. The job at the BDA was a very good fit for me in that what the BDA does as an organisation is very similar to what the BMA does, albeit on a different scale, but it also offered new challenges.

Whilst I had very transferable skills and experiences, there was still the challenge of something new and different for me.

\section{After becoming Acting Chief Executive in August 2018, you took on the position permanently in February 2020 just as the country was about to go into national lockdown - how would you describe this first year in the post?}

The past year was not quite what I was anticipating! It's been dramatic for all of us. It's been difficult and challenging but ultimately I think, rewarding.

I was only in post for a month or so when we went into lockdown and from our perspective, we were all working from home and that brought its own significant challenges, but I am proud of the way that the BDA responded to that challenge of what we needed to do to serve members, and doing it in an unexpected environment.

Staff and members have risen to that challenge.

\section{What have been the most challenging and rewarding aspects of the job?}

The biggest challenge has been adapting to supporting members whilst working remotely, and the sheer intensity of the work across the middle period of 2020 was like no other time in my career.

Members of the profession were understandably very anxious and we needed to be there to offer the support and advice that they expected from us.

I am still involved in the stuff around discussions on things like NHS contract and these have continued intensively in England and across the four nations. All of our communications and lobbying work has been hugely challenging. It's felt almost like we've concertinaed several years of activity into the space of a year.

Discussions around changing contractual frameworks that would take a long time have necessarily been done very quickly. We've been under pressure to deliver that with the same staff resource within the BDA and the same level of member involvement.

We may not have got everything right, but the way the organisation, the way that staff and elected members have risen to that challenge, is hugely rewarding.

Did you enter the job with your own ideas and plans of what you wanted to do, and have some of these ideas had to be put on hold due to the pandemic?

I've got ideas about things that we should all want to be focusing on, but the pandemic has inevitably got in the way of that future focus.

You could say that we've been fire-fighting for almost a year and we've had less chance to get our heads up and look to the future.

With organisations like the BDA, it is quite right that our elected board sets out strategic direction on behalf of members, but like website development. We've had huge amounts of traffic and interaction throughout the last year with the BDA website, but nevertheless, modernising it is one of our key means of keeping in touch with members.

We are also focusing heavily this year on equality diversity inclusion (EDI) work.

\section{Can you explain just how much the pandemic has changed how the BDA works and how it helps its members?}

We are all essentially home working at the moment and have been for a year. We were quite fortunate in terms of making that transition because quite a few of our advice teams were already home work-based and many of us already worked occasional days at home, so it wasn't the huge transition that it might have been for some organisations.

From a supporting members' perspective, we made a conscious decision to keep not just members but the wider dental community informed of what was going on throughout the year, sharing what we could when we knew it and on our website we set up a live update feed.

That went down exceptionally well and became a kind of go-to place for information across the dental world. Across the four nations we were posting a handful of updates each day and latest news about things that were happening. It really took off.

Our website is not perfect but it certainly served a purpose at that time and we had huge

\section{'We had 1.5 million users of the website in the year and 150,000 page views a day at the peak'}

when it works well, there's a very effective partnership between the staff, the senior staff within the organisation, and those elected members as to the direction of travel.

We have a three-year strategic plan and we should have been starting that around now for the next period, but we have deliberately put that on hold as things stabilise because we don't know where the economy is, we don't know where the profession is going to be and we need some clarity about where we are, as we look to the future as an organisation.

There are still some areas I want us to focus on from an operational perspective - things growth in use. We had 1.5 million users of the website in the year, which is a huge increase, and 150,000 page views a day at the peak.

The routine work - advising and supporting members - we helped with as much as we could and those advice teams got exceptionally busy this time last year.

We introduced some additional services. For example, when associates were not being necessarily paid as they should be, we provided a new dispute resolution service.

We were trying to do what we could to adapt and to support members through very difficult times. 
14 Because the BDA is a democratic organisation, we have got lots of committees and representatives serving their members and that is a structure that has also had to go completely remote. We have all got used to Teams and Zoom and all these platforms to keep decision-making and discussions going, with many online meetings with NHS England, CDOs, the Department of Health and Social Care, ministers and the devolved nations' governments.

\section{Will the BDA adjust its operations permanently because of the changes that have had to be made during the pandemic?}

Like lots of organisations, I think as we come out of the pandemic, we are likely to see more home working and I think we'll see something of a hybrid approach. The norm

\section{Do you think dentistry has been hit badly because of the pandemic?}

The spring of last year was really tough for dentistry, when practices were largely closed to face-to-face care and particularly those practices relying on private income were struggling quite badly.

Whilst I am proud of the BDA's role, we were more successful in protecting NHS earnings than we were in protecting private earnings, which was not for the want of trying. NHS practices may well now be struggling, in England particularly, as they face increased delivery expectations despite ongoing restrictions in place.

I think by necessity there have been signs of a strong recovery, particularly for private dentistry, so I would hope that it is a sector that will come out of the pandemic strongly.

\section{'I think that dentists and teams have really gone above and beyond what you might expect.'}

is likely to be more time at home for people, blended with the office, although we need to go through the process of consulting staff on exactly how they see things.

Once we get through the social distancing bit, I think it's going to bring interesting challenges for lots of organisations about how they use their office space in the future.

On the approach to representation and the whole BDA committee structure, I think there are opportunities there to use the best of remote meetings to engage and involve more people.

I would hope that we can retain some of that enthusiasm and involvement. Inevitably, some of the process needs to be a bit social and there needs to be that interaction, so we need to get that right blend between faceto-face and the use of technology, both for representational work and the local branch and section activity as well.
I'd say it's oral health rather than dentistry that has been particularly badly affected by the pandemic. Because we had the period of closure and we had a backlog of care built up, you can see that there is now - and probably still building - an adverse impact on the oral health of the nation which might be there for some time.

\section{Have dentists and dental care professionals risen well to the challenges of the pandemic?}

Absolutely. There was some public and patient frustration at the closure of dentistry and then reduced availability of dentistry during the summer, but it's a case of 'you don't know what you've got till it's gone'.

I think that dentists and teams have really gone above and beyond what you might expect. It's been challenging for organisations like the BDA to move to supporting members working at home, but that is nothing compared to teams that have gone into unfamiliar circumstances, with risk attached to providing care to patients who may have COVID, the difficult circumstances around additional PPE, and the requirements on infection prevention and control.

They really bought into that urgent care provision and the ways that volunteers stepped forward for that and roles in wider NHS care when practices were shut. We had thousands of volunteers for wider roles in the NHS at that time and then beyond that into the vaccination programme, lots of stories about volunteers getting involved.

Overall, I think the profession has done itself proud.

How do you see the role of the BDA in the future and how might it change or evolve?

Fundamentally, my perception is that there will remain a need for a trade union and a professional body. I don't think that will change. There needs to be a voice and an advocate for oral health, for patients and for the profession.

What will inevitably change is how we do it. That needs to evolve and we need to adapt to what might be a changing environment.

There are all sorts of things that you might consider that may change over the coming years.

Will the core way that general dental practice is provided remain in place or will it change?

Will the growth in corporate dentistry continue and therefore will we see fewer practice owners, will we see more associates and what will their employment status be? Will it change to being more employed dentists?

What about the BDA's relationship with the wider dental team?

These are all quite fundamental questions about what we are.

We also have to look at how members want to receive their advice and information in the future and how they will want to interact with us and with each other. 